Thorax (1947), 2, 58

\title{
CAVERNOUS HAEMANGIOMA OF THE LUNG
}

\author{
BY \\ W. WHITAKER \\ Leeds
}

Cavernous haemangiomata of the lung are rare, and a survey of the French, American, and English literature on the subject has revealed only five cases.

In 1936 Bowers reported the case of a baby boy who, two days after birth, became extremely dyspnoeic and died within a few minutes. At autopsy there were many branching raised areas on the surface of both lungs. These were filled with blood and histologically proved to be angiomatous masses. Death was due to the rupture of one of these angiomata into the left pleural cavity. Further details of the autopsy were not reported, and whether or not other haemangiomata existed in this child is unknown.

Rodes, in 1938, described the case of a man aged twenty-five whose symptoms had been dyspnoea and cyanosis. Clubbing of the fingers had been noted at the age of fifteen. When he was seen shortly before his death the lips were dark and purplish, with several small spots on each, resembling haemangiomata. No abnormal physical signs were detected in the heart or lungs. A blood count showed a polycythaemia, the haemoglobin content being 118 per cent and the red cell count 7,540,000 per c.mm. Radiography of the chest showed nodular opacities in the left middle zone. Five months after the patient had been first seen, he had two small haemoptyses followed by a severe pulmonary haemorrhage and died. At autopsy there were multilocular haemangiomata of both lungs, and death was due to rupture of one of these into a bronchus.

Another case of haemangioma of the lung in a girl of seventeen was published by Duvoir and others in 1939. She had been observed clinically and radiologically over a period of six years. She was known to have congenital syphilis, and had a bilateral asymmetrical congenital abnormality of her hands, multiple lipomata, and a history of paroxysmal dyspnoea. Death was due to pneumonia, and at autopsy a haemangioma was found to occupy the whole of the lower lobe of the left lung. There were similar tumours in other viscera.

In 1942 Hepburn and Dauphinee reviewed the three cases described above and reported one other. This woman, aged twenty-three, presented dyspnoea, cyanosis, and clubbing of the fingets.' Radiographic examination of the chest." revealed an infiltrating process in the right middle and lower lobes." Examination of the blood showed a polycythaemia, the haemoglobin content being 140 to 146 per 
cent and the red cell count $\mathbf{9 . 0}$ to $\mathbf{9 . 6}$ million per c.mm. Right pneumonectomy was performed, and angiomatous masses were found in the middle portion of the lower lobe of the removed lung. The polycythaemia disappeared rapidly after pneumonectomy. No mention was made of the presence of other haemangiomata.

In 1943 Janes reported the case of a man, aged thirty, who had been successfully treated for multiple cavernous haemangiomata of the lung by local resection of the tumours, two being removed from each lung. This patient had recurrent haemoptysis. Physical examination showed cyanosis of the lips and nail-beds, multiple haemangiomata on the lower lip, and a soft blowing murmur in the right cardio-phrenic angle.

\section{Case RePORTS}

The following two cases, in which a clinical diagnosis of cavernous haemangioma of the lung was made, were recently under the care of Mr. P. R. Allison.

Case 1.-A woman, aged forty-four, had an "influenzal " attack in January, 1944, an... which she developed a cough and pain in her chest. When first seen in March, 1944, she complained of dyspnoea and a slight cough with some sputum. There was a previous history of frequent nose-bleeding, which had occurred also in one of her brothers. On examination she had cyanosis, parrot-beak clubbing of the fingers, and many telangiectases on her face which were said to have been always present. No abnormal physical signs were detected in the heart or lungs. Radiography of the chest showed an opacity in the postero-anterior view alongside the heart shadow in the right lung field, and in the lateral view two rounded opacities behind and below the hilum (Figs. 1 and 2). No tubercle bacilli or malignant cells were found in the sputum. Examination of the blood showed some polycythaemia, the haemoglobin content being 96 per cent, and the red cells 6,300,000 per c.mm.; the white cell count was normal. Bronchoscopically a few telangiectases were noted in the interarytenoid space, but none were seen in the trachea or bronchial tree, nor was any other abnormality noted.

In September, 1944, right thoracotomy was performed ; opening of the pleura revealed a huge vascular mass in the lower lobe. The inter-lobar septum was opened and the lobe root exposed. The pulmonary artery of the lower lobe was seen to be abnormally large ; it was doubly ligatured, stitched, and divided. When this had been done there was still pulsation in the lobe, which did not disappear until the inferior pulmonary vein had been clamped and ligatured. The lobectomy was completed and the chest closed with an underwater drain. Post-operatively, progress was entirely satisfactory until the sixth day, when, after asking for a bed pan, the patient collapsed and died within fifteen minutes. Death was assumed to be due to pulmonary embolism. Unfortunately no autopsy was obtained, and it is not known whether there were other visceral haemangiomata.

The lobe which had been removed contained a cavernous haemangioma, the huge vessels of which were in direct continuity with the inferior pulmonary vein of the right side. This specimen (Fig. 3) was examined by Prof. M. J. Stewart, who made the following report: "The vessels involved in the angiomatous process are venous in structure. They are all thin-walled, some of them very much so. The largest vessel which was sectioned measures fully $1 \mathrm{~cm}$. in diameter, and its wall in places is no more than 30 or $40 \mu$ thick ; elsewhere it is several times this thickness. In the basal portion, containing many small vessels (Figs. 4 and 5), there is evidence of extensive haemorrhage into the lung substance 


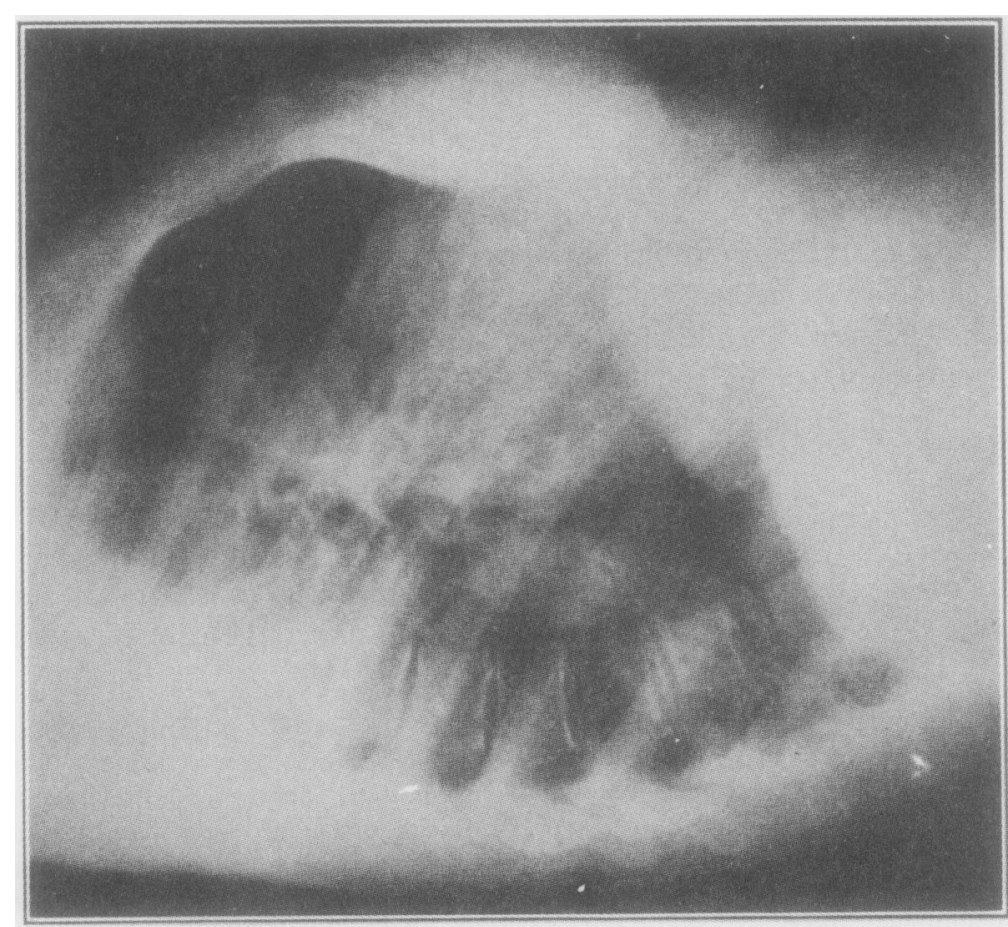

.

은?

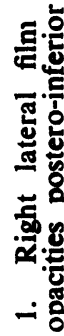
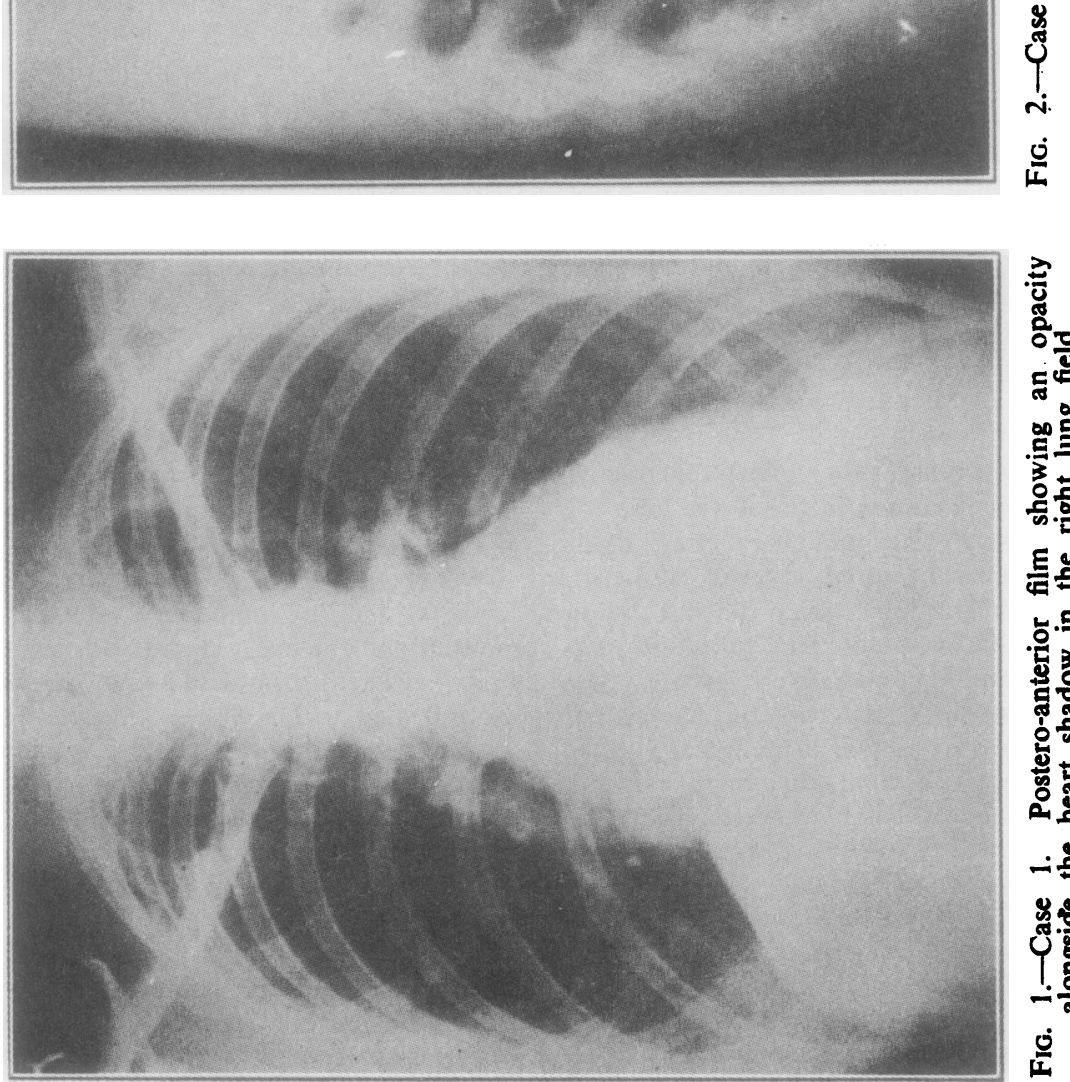

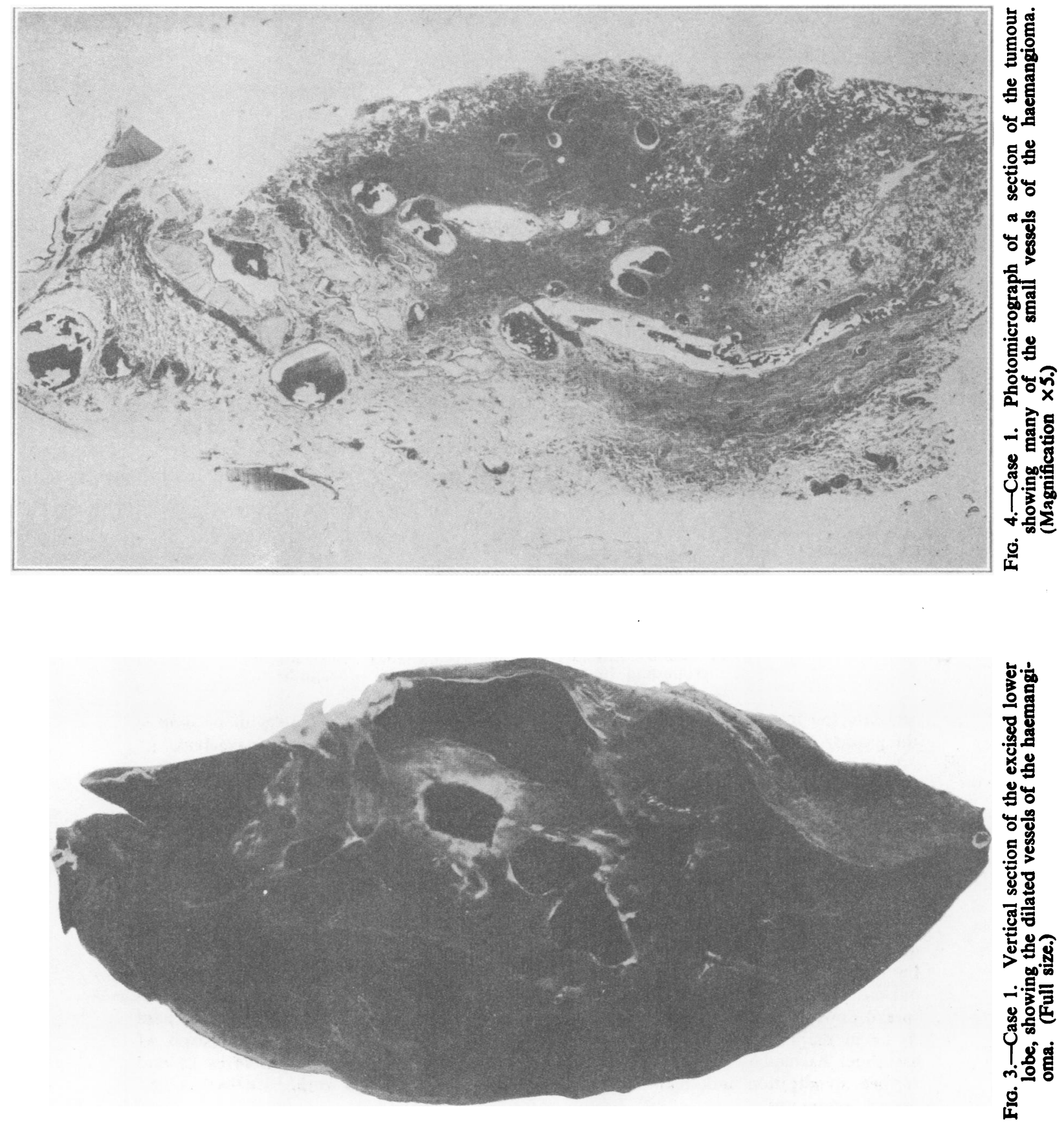


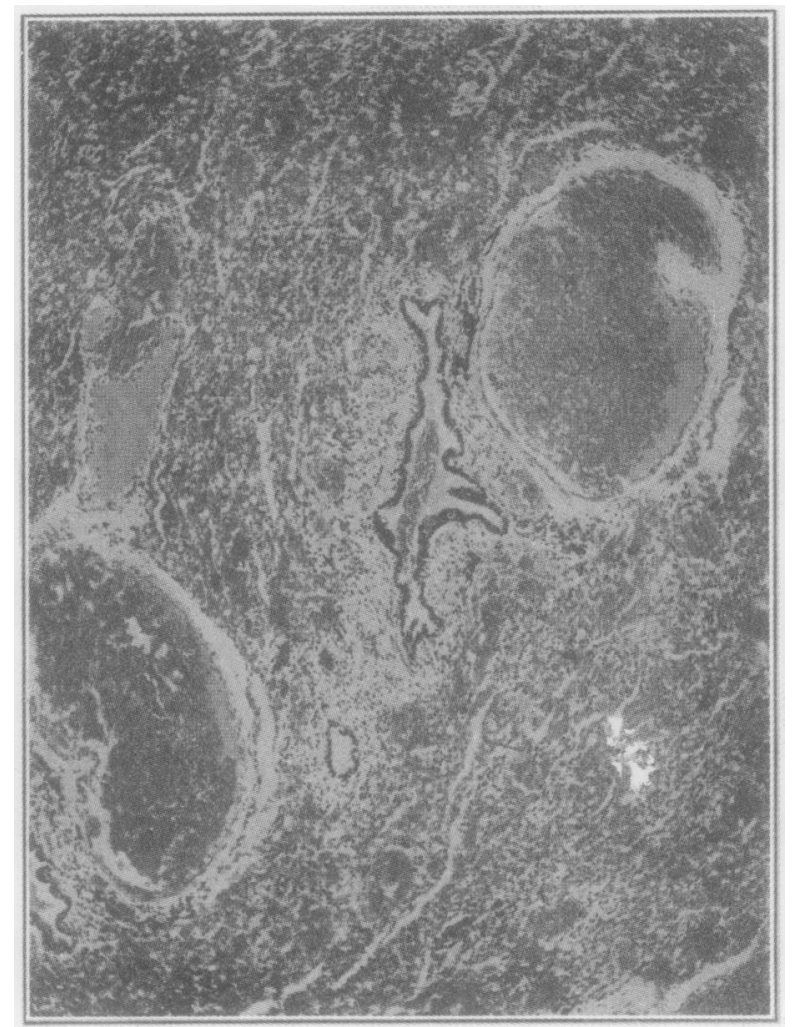

FIG. 5.-Case 1. Photomicrograph of two small radicles of the haemangioma showing the thin-walled vessels of venous structure and the haemorrhage into the surrounding lung tissue and bronchiole. (Magnification $\times 50$.)

and into the interior of many of the bronchi and bronchioles. Other portions of lung in the vicinity of the angiomatous process show collapse, with great vascular engorgement."

Case 2.-A man, aged thirty-three, first attended hospital complaining of fibrositic pain in the neck and in both shoulders and both arms. On examination, several telangiectases were noted on the cheeks and lips, and a few on the soft palate. There were presumably others on the nasal mucosa, for on further questioning the patient admitted that he had nose-bleeding almost every month. He also volunteered the information that his father had suffered from nose-bleeding. The only abnormal sign in the chest was a harsh murmur of maximum intensity in the left fourth and fifth spaces in the mid-axillary line; it appeared to be independent of the heart sounds, was exaggerated by inspiration, and radiated uniformly around the point of maximum intensity for about two inches. There was no clubbing of the fingers. Radiography of the chest showed a clump of worm-like opacities extending outwards from the left hilum (Fig. 6). On the postero-anterior radiograph these opacities spread downwards and outwards from the hilum, and in the lateral (Fig. 7) they appeared to be in the lingular region. On this clinical and radiological evidence a diagnosis of cavernous haemangioma of lung was made. As the patient was symptom-free he refused further investigation and treatment and was allowed to return to work. He has had no further symptoms. 

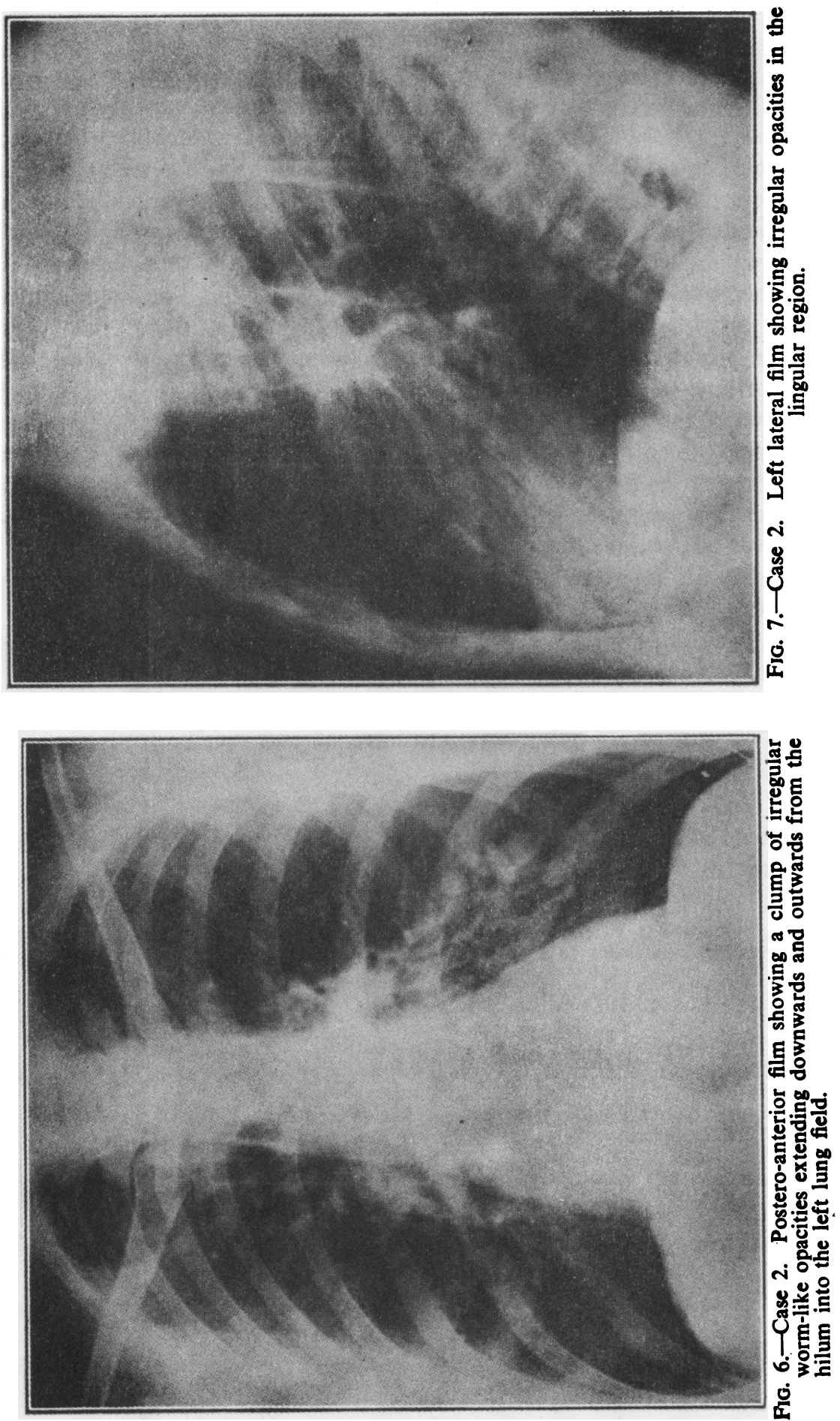
Discussion

In the cases reviewed and reported above, the following features have been noted: (1) non-specific cardio-respiratory symptoms, especially dyspnoea and haemoptysis ; (2) cyanosis ; (3) polycythaemia and finger clubbing ; (4) exocardial murmurs in the chest: (5) telangiectases on skin, mucous membranes, and other viscera ; (6) irregular circinate opacities in the lung fields on radiography.

The cyanosis which occurs in these cases is presumably due to the shunt effect of the tumour deviating blood from the pulmonary artery into the pulmonary vein without transmission through the alveolar capillaries. The finger clubbing and the polycythaemia develop as secondary manifestations of the systemic anoxaemia, which is also responsible to some degree for the dyspnoea. The presence of other telangiectases is the most helpful feature in diagnosis. In five out of seven of the cases here reviewed, mention of these is made. The sites of election appear to be the face, lips, and soft palate. This association of cavernous haemangioma of the lung with multiple telangiectasia suggests that the lung lesion is also one of hereditary telangiectasia. In the two cases reported, conclusive evidence was not obtained to prove the hereditary background, as facilities were not available for interviewing the relatives, but suggestive evidence of nosebleeding was obtained in both histories.

Where the lesions are situated so that complete removal is possible it appears desirable to remove the affected portion of the lung, either by local resection, by lobectomy, or by pneumonectomy. If operation is postponed there will be the constant risk of a severe pulmonary haemorrhage and sudden death.

\section{SUMMARY}

Two cases of cavernous haemangioma of the lung are reported, and five cases in the literature are reviewed.

I wish to thank Mr. P. R. Allison for the encouragement he gave me in preparing this paper, and for his permission to report the two cases under his care.

\section{REFERENCES}

Bowers, W. F. (1936). Nebraska med. J., 21, 55.

Duvoir, M., Picot, G., Pollet, L., and Gaultier, M. (1939). Bull. Mem. Soc. med. Hôp. Paris, 55, 596.

Hepburn, J., and Dauphinee, J. A. (1942). Amer. J. med. Sci., 204, 681.

Janes, R. M. (1943). Brit. J. Surg., 31, 270.

Rodes, C. B. (1938). J. Amer. med. Ass., 110, 1914. 